\title{
Synthesis and Characterization of Cobalt Ferrite through Co-Precipitation Technique
}

\author{
Subramanian Nithiyanantham 1,*(D), Selvaraj Viviliya ${ }^{1}{ }^{(\mathbb{D})}$, Somasundaram Anandhan ${ }^{1(\mathbb{D})}$ \\ Sreepathi Mahalakshmi ${ }^{2}$ (D) \\ 1 Post Graduate \& Research Department of Physics, (Applied Energy Resource Divisions), Thiru. Vi. Kalyanasundaram \\ Govt Arts and Science College, Thiruvarur, Tamilnadu, India \\ 2 Post Graduate \& Research Department of Physics, Ethiraj College for Women, Chennai, Tamilnadu, India \\ * Correspondence: s_nithu59@rediffmail.com;
}

Scopus Author ID 34768710400

Received: 4.08.2020; Revised: 20.09.2020; Accepted: 24.09.2020; Published: 3.10.2020

\begin{abstract}
The device formation in current technology demands effective magnetic materials. Cobalt ferrite nanoparticles were synthesized by the co-precipitations method using the precursor materials $\left(\mathrm{Fe}\left(\mathrm{No}_{3}\right)_{3} \quad 9 \mathrm{H}_{2} \mathrm{O}\right)$ and $\left(\mathrm{Co}\left(\mathrm{NO}_{3}\right)_{2} \quad 6 \mathrm{H}_{2} \mathrm{O}\right)$. X-ray diffraction (XRD), Fourier Transform Infrared Spectroscopy (FTIR) analysis, and UV-Visible absorption spectral studies were used to analyze the structural, chemical/functional groups with possible stretching and optical bandgap properties of the $\mathrm{CoFe}_{2} \mathrm{O}_{4}$ powder. XRD results designate that the resultant particles are crystalline, pure single-phase spinel structure. From the FTIR analysis reveals that $\mathrm{C}-\mathrm{C}, \mathrm{C}=\mathrm{O}$ stretching, and the shift is leaked indicating that the presence $\mathrm{CoFe}_{2} \mathrm{O}_{4}$. The absorption and the optical band gaps values are increased trend with temperatures also evidence that is enhancing magnetic behavior.
\end{abstract}

Keywords: ferrite; XRD; FTIR; UV; bandgap.

(C) 2020 by the authors. This article is an open-access article distributed under the terms and conditions of the Creative Commons Attribution (CC BY) license (https://creativecommons.org/licenses/by/4.0/).

\section{Introduction}

Cobalt with magnetite plays a reasonable role in insensing processes such as chemical sensors, thermal sensors, magnetic sensors and etc. The peculiar property of the anisotropic nature of cobalt with $\mathrm{Fe}$ the susceptibility values exist in less one. But enhancing Co gives the susceptibility that goes greater than one may be used for novel sensing purposes [1-4]. $\mathrm{Co}_{3} \mathrm{O}_{4} \mathrm{is}$

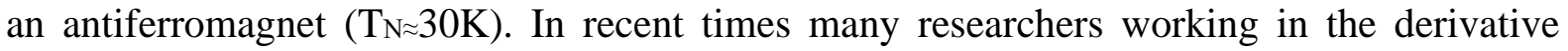
compound of $\mathrm{Co}_{3}-\mathrm{xMxO}_{4}[\mathrm{M}=\mathrm{Fe}, \mathrm{A} 1, \mathrm{Mn}]$ [5]. The properties of compounds with Fe give variety/diverse applications through different magnetic nature such as para, ferro, anti-ferro, and ferric natures [6]. Spinel ferrite $\left(\mathrm{MFe}_{2} \mathrm{O}_{4}\right)$ magnetic nanocomposites have fascinated much responsiveness owing to their distinctive magnetic assets and chemical stability. There are many ways of preparing nanoparticle with many ways sol-gel [7], co-precipitation [8] and etc.,

In this investigation, the author focuses on spinel, mainly spinel stability, with a range of temperatures (above $900 \mathrm{oC}$ it gradually decreases). The isotropic behavior of Co ion can change depends on the size and the nature of preparation processes [9]. To achieve this, we have synthesized cobalt ferrite magnetic nanoparticles through the co-precipitation method and characterized by using X-ray diffraction (XRD), Fourier transforms infrared (FT-IR), and UVvisible (UV-vis) spectroscopy through which determined the optical band gap of cobalt ferrite magnetic nanoparticles [10]. 


\section{Materials and Methods}

\subsection{Sample preparation.}

The nanoparticle $\mathrm{Co}_{2} \mathrm{FeO}_{4}$ were prepared by the chemical co-precipitation method [8]. The precursor material used was Iron (III) nitrate with Cobalt(II) nitrate was taken by 1:2 ratio of AR grade chemicals procured from S.D. Fine chemicals, Mumbai, India(Table.1). The mixed solution stirred well using a magnetic stirrer about $6 \mathrm{hr}$ with temperature $80^{\circ} \mathrm{C}$ and maintained their $\mathrm{pH}(11)$ by the addition of Potassium hydroxide $(\mathrm{KOH})$. Finally, the sample precipitate was found at the bottom of the beaker.

Table 1. Properties of the precursor material.

\begin{tabular}{c|c|c|c} 
Sample & $\begin{array}{c}\text { Molecular } \\
\text { weight }(\mathbf{g} / \mathbf{m o l})\end{array}$ & Melting point $\left({ }^{\mathbf{0}} \mathbf{C}\right)$ & $\begin{array}{c}\text { Curie temperature } \\
\left({ }^{\mathbf{0}} \mathbf{C}\right)\end{array}$ \\
\hline Iron (III) nitrate & 404.00 & 47.2 & 858 \\
\hline Cobalt(II) nitrate & 291.04 & 99.6 & 1121 \\
\hline Potassium hydroxide & 56.11 & 406 & 240
\end{tabular}

The resultant precipitate was cleaned with pure water and kept at $70^{\circ} \mathrm{C}$ temperature for 8 hours. The as-prepared sample was annealed at $400^{\circ} \mathrm{C}-600^{\circ} \mathrm{C}$ and $800^{\circ} \mathrm{C}$ for 6 hours. These nanoparticles were characterized by various techniques.

\subsection{Experimental techniques.}

The structural analysis was carried out through Philips analytical X-ray diffractometer $\left(\lambda=1.5401 \mathrm{~A}^{\mathrm{o}}\right)$. The FT-IR spectrum taken through the PerkinElmer spectrometer ranges from 500 to $4,000 \mathrm{~cm}^{-1}$. The UV absorption studies were carried out through UV-2600, Shimadzu [11].

\section{Results and Discussion}

\subsection{XRD analysis.}

The XRD pattern of the investigated $\mathrm{Co}_{2} \mathrm{FeO}_{4}$ sample is shown in fig.1(a)-(d). The nonexistence of peaks lines corresponds to the $\mathrm{Co}_{2} \mathrm{FeO}_{4}$ phase following heated samples at the various thermal condition. It has been observed that all the patterns split into two components for treated samples excluding at temperature $800^{\circ} \mathrm{C}$. While comparing the peak position of all patterns, it evidence that the compound $\left(\mathrm{Co}_{2} \mathrm{FeO}_{4}\right)$ is the spinel one.

The splitting of spectral lines is noted in Fig.1 (ranges from 20 to 80) and clearly shown for (311) XRD peak line alone in the right-hand side of Fig.1. The peak positions at higher and lower $2 \theta$ values are denoted at $2 \theta_{2}$ and $2 \theta_{1}$, respectively. The pattern for the untreated sample shown more splitting, and it is decreasing gradually closer and closer, and finally, it disappears at $800^{\circ} \mathrm{C}$, suggesting a single phased compound.

There is a coexistence of two spinel phases confirmed from the lattice parameter a1 and a2 determined through $2 \theta_{1}$ and $2 \theta_{2}$, of the spectrum are presented in Table 2 . The lattice parameter of the $800^{\circ} \mathrm{C}$ sample is a fair and good arrangement with theoretical value and experimental value. 

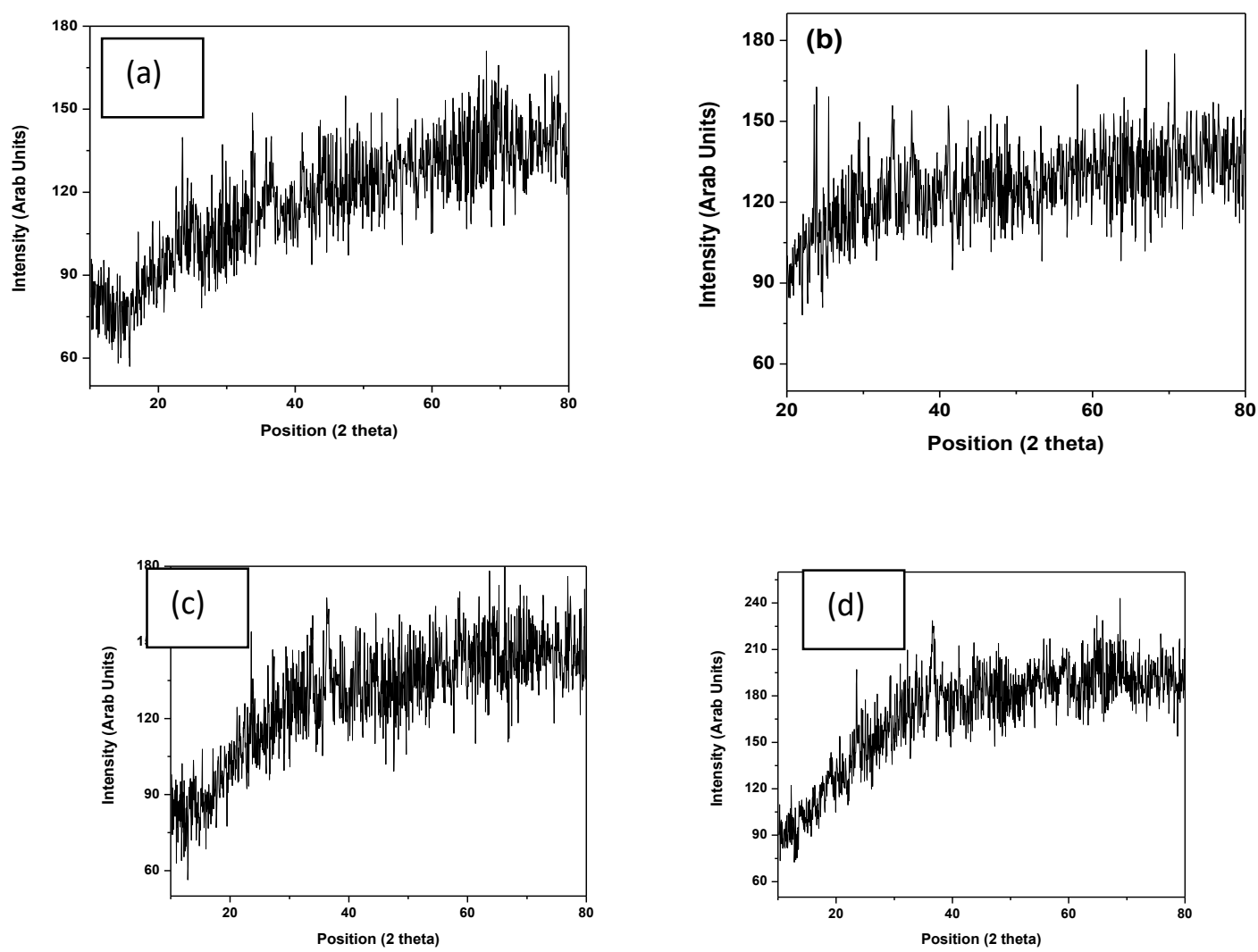

Figure 1. XRD spectra of at (a) room, (b) 400, (c) 600 and (d) $800{ }^{\circ} \mathrm{C}$ temperature.

It can be seen that the lattice parameter a1 decreases as the temperature increases from $400^{\circ} \mathrm{C}$ to $800^{\circ} \mathrm{C}$. Both (a1 and a2) are coinciding with $800^{\circ} \mathrm{C}(\mathrm{S} 90)$ sample.

Table 2. Crystallite size and lattice parameters.

\begin{tabular}{l|c|c|c|c|c} 
Sample & $\mathbf{2 \theta}_{\mathbf{1}}$ & $\mathbf{2 0}_{\mathbf{2}}$ & $\begin{array}{c}\text { Crystalline size } \\
\mathbf{( n m})\end{array}$ & $\begin{array}{c}\text { Lattice } \\
\text { parameters a1 }\end{array}$ & $\begin{array}{c}\text { Lattice } \\
\text { parameters a2 }\end{array}$ \\
\hline As-perpared & 36.41 & 36.60 & 11.09 & 8.184 & 8.226 \\
\hline $800^{\circ} \mathrm{C}$ & 36.72 & 36.27 & 13.9 & 8.079 & 8.281
\end{tabular}

The particle size of the samples was calculated through well known Debye-Scherrer formula:

$$
D=0.89 \lambda / \beta \cos \theta
$$

$\left(\lambda=1.504 \mathrm{~A}^{\circ}\right), 2 \theta$ - peak position, D - particle size, $\beta$ - FWHM) on (311) XRD peak at $2 \theta$. The determined particles are in the nano range $(\sim 11 \mathrm{~nm}$ to $15 \mathrm{~nm})$ is due to various grain growth induced by the thermal energy of different annealing temperature $[12,13]$. The crystalline size and lattice parameters of both as-papered and various annealed samples are as shown in the same Table 2.

\subsection{FTIR investigation.}

Figure 2 reveals that the FTIR spectra for the power sample heat traced at various temperatures. The FTIR spectrums of $\mathrm{Co}_{2} \mathrm{FeO}_{4}$ were recorded in the range $500-4000 \mathrm{~cm}^{-1}$. The broad absorption peak at $3350 \mathrm{~cm}^{-1}$, which corresponds to the $\mathrm{O}-\mathrm{H}$ stretching vibration, arises from the molecules of the aqueous environment. The peak located at $2391 \mathrm{~cm}^{-1}$ is due to +ve atmosphere $\mathrm{CO}_{2}$ present in the instrument stretching modes of $\mathrm{C}-\mathrm{C}$ and $\mathrm{C}=\mathrm{O}$ are observed of $1374 \mathrm{~cm}^{-1}, 1638 \mathrm{~cm}^{-1}, 1760 \mathrm{~cm}^{-1}$, respectively. The band of $2391 \mathrm{~cm}^{-1}$ is ascribed to $\mathrm{C}-\mathrm{H}$ 
stretching vibration. The peak shift observed around $550 \mathrm{~cm}^{-1}$ indication of the $\mathrm{Co}_{2} \mathrm{FeO}_{4}[14$, 15]. Further, there is more absorption in annealed samples rather than as prepared.

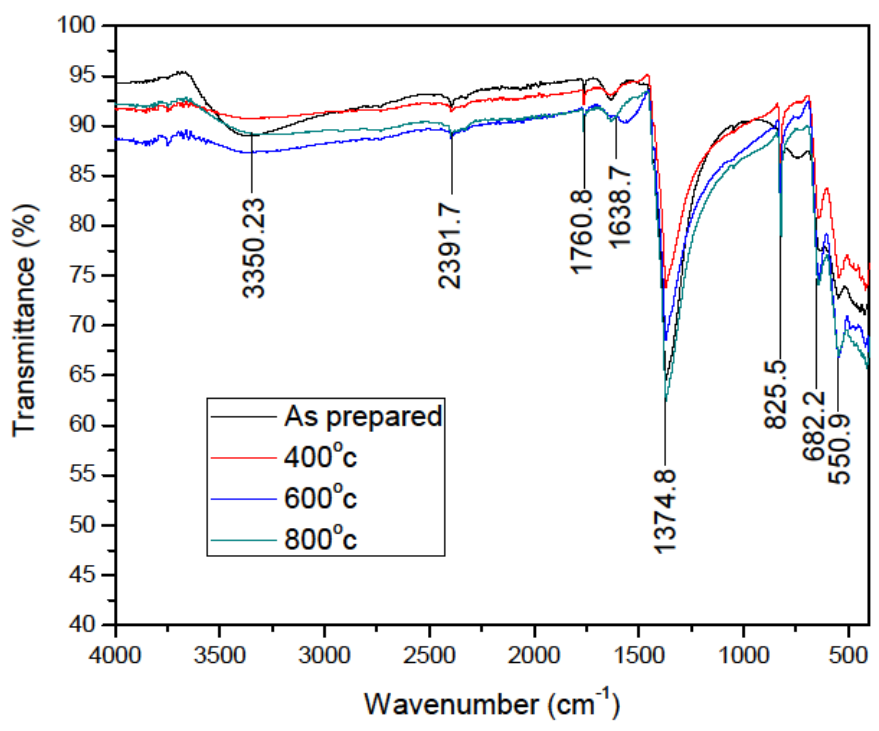

Figure 2. FTIR Spectra of $\mathrm{CO}_{2} \mathrm{FeO}_{4}$ at various temperatures.

\section{3. $U V$-vis spectrometer $(U V)$.}

The UV-visible absorption has been used to monitor the optical properties of quantum -sized particles. The fig 3 shows the absorption spectrum for $\mathrm{Co}_{2} \mathrm{FeO}_{4}$ nanoparticles of both as-prepared and annealed at temperatures $400^{\circ} \mathrm{C}, 600^{\circ} \mathrm{C}$, and $800^{\circ} \mathrm{C}$, respectively.

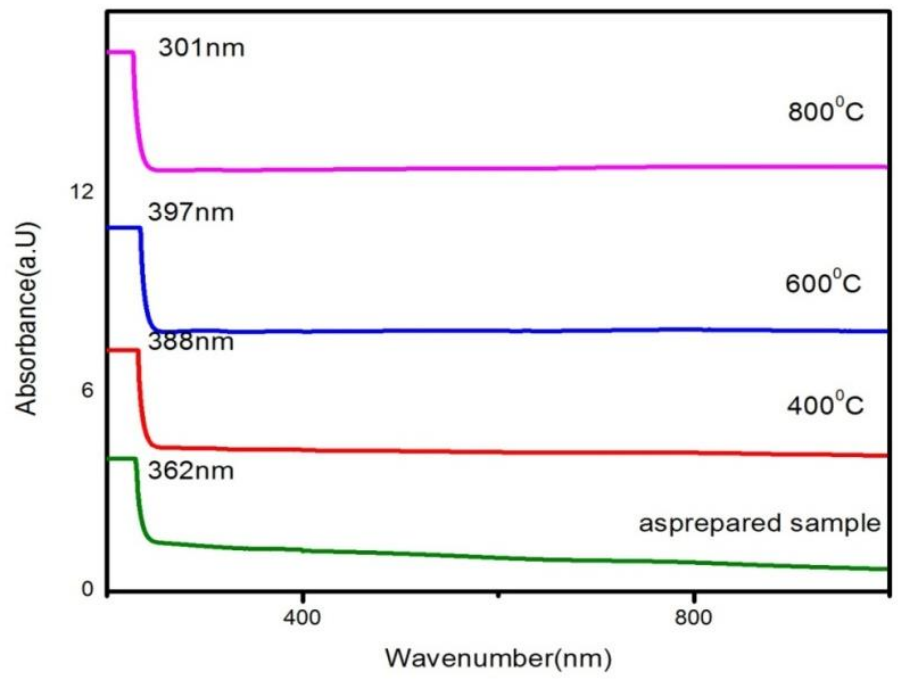

Figure 3. UV-vis absorbance spectra of $\mathrm{Co}_{2} \mathrm{FeO}_{4}$.

The absorption spectra of both samples had a primary narrow peak and were found below 400nm. In addition to that, there are several numbers of shoulder peaks where observed in the visible range of the absorption spectrum. Absorption is depending on the temperature when increasing the temperature absorption gets decreased that is shown the same fig. 3 . particle size increased absorbance decreased. The table shows the measurement from the UVvis spectrometer. 
Table 3. Absorbance and visible spectra.

\begin{tabular}{l|c|c} 
Sample & Absorbance & Band gap $(\mathbf{e V})$ \\
\hline As prepared & 362.9 & 3.41 \\
\hline $400^{\circ} \mathrm{cm}$ & 388.8 & 3.19 \\
\hline $600^{\circ} \mathrm{cm}$ & 397.5 & 3.12 \\
\hline $800^{\circ} \mathrm{cm}$ & 301.0 & 4.12
\end{tabular}

\subsection{Estimation of optical band gap.}

Absorption in UV-vis spectral studies in the UV-Vis-NIR region was carried out to estimate the optical band gap $\left(E_{\mathrm{g}}\right)$ of the synthesized samples under study. These values are obtained through the well-known relations given by tauc and wood is given by,

$$
\alpha h v=\beta\left(h v-E_{g}\right)^{n / 2}
$$

Where,

A - absorbance constant, $\mathrm{h}$ - plank constant and t- thickness of the cuvette and $\mathrm{v}$ - frequency of UV source. The required $\mathrm{E}_{\mathrm{g}}$ is the optical band gap, and $\mathrm{n}$ is the constant corresponds to different types of electronics transitions.

The calculated optical band gap of $\mathrm{Co}_{2} \mathrm{FeO}_{4}$, both as-prepared and annealed samples of range (3-4.2ev), are presented in Table 3. It is shown that when increasing the temperature, the optical band gap also increased due to the transformation of the phase structure - similar results were reported by some researchers $[16,17]$.

\section{Conclusions}

From the above analysis, the following conclusions arrive, $\mathrm{CoFe}_{2} \mathrm{O}_{4}$ at as prepared and $400^{\circ} \mathrm{C}, 600^{\circ} \mathrm{C}$, and $800^{\circ} \mathrm{C}$ were grown by the co-precipitation method. X-ray diffraction analysis substantiates the formation of a single-phase cubic spinel structure with nano-sized ferrites. The small change in lattice parameter with Co, may due to Co ions occupying $\mathrm{Fe}$ position in the lattice were also confirmed. The observed absorption bands divulge that the formation of spinel shape. Absorption measurements were performed with UV confirmed the optical bandgap of investigated samples.

\section{Funding}

This research received no external funding.

\section{Acknowledgments}

The authors are grateful to acknowledge the college authorities provided the necessary facility to complete this work.

\section{Conflicts of Interest}

The authors declare no conflict of interest.

\section{References}

1. Gabriel, L.; Mariella, A.; Cynthia, C.; Cabriel, B.; Jochen, L.F.; Elisa, B.S.; Internal structural and magnetic properties in Cobalt Ferrite Nanoparticle: Influence of the synthesis method. Particle and Particle system characterization, 2019, 36, 1900061. 
2. Bastami, T.R.; Entezari, M.H.; Hu, Q.H.; Hartono, S.B.; Qiao, S.Z. Role of polymeric surfactants on the growth of manganese ferrite nanoparticles. Chemical Engineering Journal 2012, 210, 157-165, https://doi.org/10.1016/j.cej.2012.08.031.

3. Supriya, S.; Kumar, S.; Kar, M. Correlation between AC and DC transport properties of Mn substituted cobalt ferrite. Journal of Applied Physics 2016, 120, https://doi.org/10.1063/1.4968795.

4. Sivakumar, M.; Kanagesan, S.; Umapathy, V.; Chinnaraj, K, Nithiyanantham, S. Study of CoFe2O4 Particles Synthesized with Various Concentrations of PVP Polymer. Journal of Superconductivity and Noval Magnetism 2013, 26, 725-731.

5. Sivakumar, M.; Kanagesan, S.; Chinnaraj, K.; Suresh Babu, R.; Nithiyanantham, S. Synthesis, Characterization and Effects of Citric Acid and PVA on Magnetic Properties of CoFe2O4. Journal of Inorganic and Organometallic Polymers and Materials 2013, 23, 439-445, https://doi.org/10.1007/s10904012-9801-X.

6. Sumanth, Y.A.; Sujatha, R.A.; Mahalakshmi, S.; Karthika, P.; Nithiyanantham, S.; Saravanan, S.; Azagiri,. Synthesis and characterization of nanophase zinc oxide materials.Journal of Material Science - Materials in Electronics, 2016, 27, 1616-1621.

7. Hayrapetyan, S.S.; Khachatryan, H.G. Porosity appearance in cobalt ferrite and changes under the thermal treatment of co-precipitated iron(II) and cobalt(II) oxalates. Microporous and Mesoporous Materials 2004, 72, 105-110, https://doi.org/10.1016/j.micromeso.2004.04.023

8. Nikumbh, A.K.; Pawar, R.A.; Nighot, D.V.; Gugale, G.S.; Sangale, M.D.; Khanvilkar, M.B.; Nagawade, A.V. Structural, electrical, magnetic and dielectric properties of rare-earth substituted cobalt ferrites nanoparticles synthesized by the co-precipitation method. Journal of Magnetism and Magnetic Materials 2014, 355, 201-209, https://doi.org/10.1016/j.jmmm.2013.11.052..

9. Jiao, Z.; Geng, X.; Wu, M.; Jiang, Y.; Zhao, B. Preparation of CoFe2O4 nanoparticles by spraying coprecipitation and structure characterization. Colloids Surface Sciecne - A 2008, 313, 31-34, https://doi.org/10.1016/j.colsurfa.2007.04.066.

10. Kiran, V.S.; Sumathi, S. Comparison of catalytic activity of bismuth substituted cobalt ferrite nanoparticles synthesized by combustion and co-precipitation method. Journal of Magnetism and Magnetic Materials 2017, 421, 113-119, https://doi.org/10.1016/j.jmmm.2016.07.068.

11. . Mahalakshmi, S.; Jayasri, R.; Nithiyanantham, S.; Swetha, S.; Santhi, K, Magnetic interactions and dielectric behavior of cobalt ferrite and barrium titanate multiferroics nanocomposites, Applied Surface Science, 2019, 494, 51-56.

12. Mustaq, M.W.; Imran, M.; Bashir, S.; Kanwal, F.; Mitu, L. Synthesis, structural and biological studies of cobalt ferrite nanoparticles. Bulgarian Chemical Communications 2016, 48, 565.

13. Rahman, O.u.; Mohapatra, S.C.; Ahmad, S. Fe3O4 inverse spinal super paramagnetic nanoparticles. Materials Chemistry and Physics 2012, 132, 196-202, https://doi.org/10.1016/j.matchemphys.2011.11.032.

14. Viviliya, S. Synthesis the characterization of cobalt ferrite by co-precipitation method, MSc, Thesis, submitted to Bharathidasan University, Tamilnadu, India, 2017.

15. Raut, A.; Barkule, R.; Shengule, D.; Jadhav, K.J. M. Synthesis, structural investigation and Magnetic Properties of Zn 2+ Substituted Cobalt Ferrite Nanoparticles Prepared by the Sol-Gel Auto-Combustion Technique. Journal of magnetism and magnetic materials, 2014, 359, 87-92.

16. Kalam, A.; Al-Sehemi, A.G.; Assiri, M.; Du, G.; Ahmad, T.; Ahmad, I.; Pannipara, M. Modified solvothermal synthesis of cobalt ferrite ( $\mathrm{CoFe} 2 \mathrm{O} 4)$ magnetic nanoparticles photocatalysts for degradation of methylene blue with H2O2/visible light. Results in Physics 2018, 8, 1046-1053, https://doi.org/10.1016/j.rinp.2018.01.045.

17. Meenal, G.; Anushree, D.; Satyabratha, M.; Dipankar, D.; Anindya, D. Surfactant based synthesis and magnetic studies of cobalt ferrite, Applied Physics, A, 2020, 126, 660. https://doi.org/10.1007/s00339-02003823-9. 